\title{
Laser therapy in dentinal hypersensitivity and periodontal treatment
}

\author{
Cheol Namgung ${ }^{1}$, Jong-Ho Lee ${ }^{2}$, Kee-Yeon Kum³, Young-Jun Lim* \\ 'Department of Prosthodontics and Dental Research Institute, School of Dentistry, Seoul National University, Seoul, Republic \\ of Korea \\ 'Department of Oral and Maxillofacial Surgery, School of Dentistry, Seoul National University, Seoul, Republic of Korea \\ ${ }^{3}$ Department of Conservative Dentistry, School of Dentistry, Seoul National University, Seoul, Republic of Korea
}

Although a laser has been introduced to implant dentistry for decades, its efficacy is still open debate. The aim of this literature review is to analyze and evaluate the efficacy of laser therapy for the treatment of dentinal hypersensitivity and periodontal conditions. (J Dent Rehabil Appl Sci 2014;30(4):307-14)

Key words: laser; hypersensitivity; periodontitis; peri-implantitis; debridement

\section{서론}

기계식 절삭 장치는 과거 100 여 년간 치과 영역에서 널리 이용되어 왔다. 점진적 연구 개발을 통해 장치는 더 작아지고 절삭 효율은 증가해 왔다. 그러나 핸드피스 또 는 초음파 스케일러에서 발생하는 진동과 소음, 이로부 터 환자가 느끼게 되는 공포는 아직도 해결되지 못한 과 제로 남아있다. ${ }^{1}$ 레이저는 이러한 기계식 접촉 장치를 대 체하는 수단으로 주목을 받아왔다.

1964년 Goldman 등이 치아 우식 치료에 레이저를 최 초로 적용하여 보고하였다. 계속해서 $\mathrm{Nd}: \mathrm{YAG}$ 와 $\mathrm{CO}_{2}$ 레 이저 등이 치의학 영역에서 적용되어 왔다. 그러나 이 두 가지 종류의 레이저는 경조직 제거에 효과적이지 못할 뿐만 아니라, 열 발생으로 인한 경조직의 국소적 용융, 균 열 및 탄화(carbonization) 등의 부작용이 발생하는 것으 로 보고되었다. ${ }^{3}$ 경조직 제거에서 가장 우수한 효과를 보 인 것은 2,940 nm 파장의 Er:YAG 및 2,790 nm 파장의 $\mathrm{Er}, \mathrm{Cr}: \mathrm{YSGG}$ 레이저이다. Er:YAG 레이저는 $\mathrm{Nd}: Y A G$

*Correspondence to: Young-Jun Lim, DDS, MSD, PhD Department of Prosthodontics, School of Dentistry, Seoul National University 101 Daehak-ro, Jongno-gu, Seoul, 110-749, Republic of Korea Tel: +82-2-2072-3816, Fax: +82-2-2072-3860, E-mail: limdds@snu.ac.kr Received: July 14, 2014/Last Revision: August 10, 2014/Accepted: August 14, 2014
레이저에 비해 물에 15,000 배 더 흡수된다. 따라서 $\mathrm{Er}$ 계 열의 레이저를 물과 함께 적용하면 경조직을 효과적으로 마멸(ablating)시킬 수 있게 된다. ${ }^{4}$ 물방울 레이저란 이름 으로 친숙하게 알려진 레이저가 바로 이러한 원리를 이 용한 것이다.

1997년 미국 FDA가 Er:YAG 레이저를 승인한 이래로, 치아 와동 형성과 지각과민 처치, 치주 치료 및 임플란트 수술 등에서 Er:YAG 레이저가 제한적으로 이용되고 있 다. 레이저는 기계식 절삭장치와는 달리 조직에 마멸, 지 혈 및 정화(detoxification) 효과가 복합적으로 작용한다. 또한 정확한 절개 및 주변 조직에 대한 최소한의 손상 발 생으로 인해 술 후 통증이 적고 회복이 빠른 장점이 있는 것으로 알려졌다. 소음과 진동이 미비하여 환자의 심리 적 편안함을 증진시키는 효과도 있다. ${ }^{1}$

그럼에도 불구하고, 많은 임상가들은 레이저 사용에 대해 아직 신중한 입장을 보이고 있는 것으로 생각된다. 레이저 장치에 대한 초기 비용 부담이 크고, 각 시술 별 로 서로 다른 종류의 레이저 장치가 필요한 것이 임상가 
들에게는 경제적 진입 장벽으로 작용할 것이다. 물방울 레이저 시술이 무통 치료나 기계적 시술을 완전히 대체 가능한 것처럼 과장·과대 광고되면서 생긴 부정적 선입 견도 원인이 될 수 있다. ${ }^{5}$ 그 무엇보다도 레이저 이용에 회의적인 가장 큰 이유는 레이저의 효과에 대한 이론적 근거가 충분하지 못하기 때문일 것이다. 본 논문에서는 지각과민증과 치주 처치에 있어 레이저가 갖는 효과에 대한 최근 연구 결과들을 되짚어보고자 한다.

\section{본론}

\section{1. 상아질 지각과민증 치료에서 레이저의 효과}

상아질 지각과민(dentinal hypersensitivity: $\mathrm{DH}$ ) 치료 에 레이저가 최초로 소개된 것은 1980년대 중반이다. ${ }^{6}$ 이후로 다양한 종류의 레이저가 $\mathrm{DH}$ 치료에 시험적으 로 이용되었다. 여기에는 Nd:YAG와 Er:YAG분만 아니 라, $\mathrm{CO}_{2}, \mathrm{He}-\mathrm{Ne}$, 그리고 Diode (GaAlAs) 레이저 등이 포함된다. 이러한 레이저들은 다양한 범위의 파장과 에 너지를 나타내는데, 파장의 경우 $632.8 \mathrm{~nm}(\mathrm{He}-\mathrm{Ne})$ 부 터 10,600 nm (Er:YAG, $\mathrm{CO}_{2}$ )까지 분포한다. Diode나 $\mathrm{He}-\mathrm{Ne}$ 처럼 낮은 출력 에너지의 레이저가 $\mathrm{DH}$ 에 나타내 는 치료 효과는 레이저가 신경에 작용하는 것과 연관된 것으로 보인다. 반면, $\mathrm{Nd}: \mathrm{YAG}, \mathrm{CO}_{2}, \mathrm{Er}: \mathrm{YAG}$ 같이 높은 출력 에너지를 갖는 레이저의 치료 효과는 상아세관의 협착이나 폐색과 관련 있는 것으로 추정된다. ${ }^{7} 1,064 \mathrm{~nm}$ 파장의 Nd:YAG 레이저의 경우 이러한 폐색 효과와 더 불어 추가적으로 신경 말단에 작용하여 $\mathrm{C}$ 와 $\mathrm{A \beta}$ 섬유를 차단한다. ${ }^{8}$

상아질 지각과민증에 대한 레이저의 임상적 치료 효 과 연구들을 살펴보면, 그 결과가 서로 상이하며 다양한 범위를 나타내고 있다. DH로 인한 불편감이 레이저 치 료로 인해 감소된 비율을 환자 또는 치아 별로 살펴보면, $\mathrm{GaAlAs}$ 레이저는 $53.3 \%-94.2 \%$ 범위를 나타내는 것으 로 보고되었다. ${ }^{9,10} \mathrm{CO}_{2}$ 레이저의 3 개월 추적 조사 결과 는 $50 \%-94.5 \%$ 범위를 보이며, ${ }^{11,12} \mathrm{Nd}: \mathrm{YAG}$ 레이저의 경우 $51.5 \%$ - $100 \%$ 의 범위를 나타내었다. ${ }^{6,13} \mathrm{Er}: \mathrm{YAG}$ 레이저의 6 개월 추적 조사에서는 $\mathrm{DH}$ 감소율이 $38.2 \%$ $47 \%$ 범위로 보고되었다. ${ }^{14,15} \mathrm{Er}: \mathrm{YAG}$ 레이저의 경우 도 입 시기가 최근이라 임상 데이터가 상대적으로 적었다.

레이저를 $\mathrm{DH}$ 치료에 적용한 임상 연구는 다수 있지 만, 무작위 비교 연구(RCT)는 2011년 기준으로 8개뿐이
다. 이들에 대한 체계적 문헌 고찰(systematic review) 결 과, 중등도 이상의 편향(bias)이 존재하는 것으로 확인 되었다. 불소 바니쉬와 같은 도포 처치제와 비교 시, 레 이저가 도포 처치제보다 $\mathrm{DH}$ 에 다소 우수한 효과를 갖 는 것으로 나타났다. 메타 분석 결과, Er:YAG 레이저(n $=2$ trials)와 $\mathrm{CO}_{2}$ 레이저 $(\mathrm{n}=1$ trial $)$ 는 도포 처치제보 다 통계적으로 유의하게 우수한 치료 효과를 나타낸 반 면, Diode 레이저( $\mathrm{n}=4$ trials)와 Nd:YAG 레이저( $\mathrm{n}=2$ trials)는 도포 처치제와 유의미한 차이를 보이지 않았다 (Fig. 1). ${ }^{16}$ 무작위 비교 연구의 수가 적고, 연구 결과간에 통계적 이질성이 크기 때문에 이러한 체계적 문헌 고찰 결과를 전적으로 신뢰하기에는 무리가 있는 것으로 보 인다.

지각 과민증 치료에는 심리적 요인도 작용하는 것으 로 보인다. 따라서 지각 과민증 치료제의 효과를 판별하 기 위해서는 위약 효과(placebo effect)도 고려되어야 한 다. 2011년 발표된 Sgolastra 등의 체계적 문헌 고찰에 의하면, 레이저를 이용한 DH 치료에서 위약 효과를 포 함한 연구는 단지 3 개뿐이며, 결과간 이질성이 커서 메 타 분석은 불가능한 것으로 나타났다.

Birang 등 ${ }^{15}$ 이 Nd:YAG, Er:YAG와 placebo 레이저 를 $\mathrm{DH}$ 치료에 이용한 결과, 6 개월 추적 조사에서 통증 감소가 각각 $91 \%, 62 \%$, 그리고 $20 \%$ 로 나타났다. 그러 나 세 그룹간 통계적 비교는 이루어지지 않았으며 특정 레이저가 더 효과적이라는 증거는 없는 것으로 나타났 다. Vieria 등 ${ }^{17}$ 은 diode와 placebo 레이저를 oxalate 및 placebo oxalate와 비교한 RCT 연구를 수행하였다. 그 결과, 네 그룹간의 유의한 차이는 없는 것으로 나타났다. Lier 등 ${ }^{18}$ 이 Nd:YAG 레이저와 placebo 레이저의 DH 치 료 효과를 비교한 연구에서도, 두 그룹간에 유의한 차이 를 보이지 않았다.

이상의 결과를 종합할 때, 상아질 지각 과민증 치료에 서 레이저는 기존의 도포성 지각 과민 처치제보다 다소 우수한 효과를 나타내는 것으로 볼 수 있다. 그러나 실 험에 사용된 레이저의 종류와 파장 및 에너지 수준이 다 양하고 데이터간 이질성이 크며 위약 효과가 충분히 고 려되지 못하였다. 따라서 레이저가 상아질 지각 과민 치 료에 효과가 있다고 보기에는 그 증거 수준이 낮다고 하 겠다. 따라서, 장기간의 추가적인 RCT 연구가 수행되어 야 하며 여기에는 표본 편향과 위약 효과까지 고려되어 야 할 것이다. 


\begin{tabular}{lr}
\hline 1.1 .1 GaALAS & \\
Vieira 2009 & $-0.15[-0.56,0.27]$ \\
Tengrungsun 2008 & $1.52[1.14,1.89]$ \\
Sicilia 2009 & $-1.13[-1.91,-0.35]$ \\
Corona 2003 & $-0.19[-0.69,0.32]$ \\
Subtotal $(95 \%$ Cl) & $0.04[-1.05,1.13]$ \\
Heterogeneity: Tau ${ }^{2}=0.00 ;$ Chi $^{2}=61.09$, df $=1(P<0.00001) ;\left.\right|^{2}=95 \%$ \\
Test for overall effect: $Z=0.08(P=0.94)$
\end{tabular}

1.1.2 Nd:YAG laser

Kara 2009

Kumar 2005

Subtotal $(95 \% \mathrm{Cl})$

$0.11[-0.52,0.74]$

Heterogeneity: Tau $^{2}=0.00 ; \mathrm{Chi}^{2}=1.02, \mathrm{df}=1(P<0.00005) ; \mathrm{I}^{2}=2 \%$

Test for overall effect: $Z=3.29(P=0.0003)$

\subsubsection{ErYAG laser}

Ipci 2009

$-1.86[-2.23,-1.50]$

Scharwa 2002

Subtotal $(95 \% \mathrm{Cl})$

$-2.54[-3.92,-1.15]$

Heterogeneity: $\mathrm{Tau}^{2}=0.92 ; \mathrm{Chi}^{2}=12.14, \mathrm{df}=1(P=0.00005) ; \mathrm{I}^{2}=92 \%$

Test for overall effect: $Z=3.29(P=0.0003)$

1.1.4 $\mathrm{CO}_{2}$

Ipci 2009

Subtotal $(95 \% \mathrm{Cl})$

$-1.71[-2.06,-1.35]$

Heterogeneity: Not applicable

Test for overall effect: $Z=9.44(P<0.00001)$

Total $(95 \% \mathrm{Cl})$

$-0.73[-1.71,0.25]$

Heterogeneity: Tau $^{2}=2.14 ; \mathrm{Chi}^{2}=276.12, \mathrm{df}=8(P<0.00001) ; \mathrm{I}^{2}=97 \%$

Test for overall effect: $Z=1.47(P=0.14)$

Test for subgroup differences: $\mathrm{Chi}^{2}=32.83, \mathrm{df}=3(P<0.00001) ; I^{2}=90.9 \%$

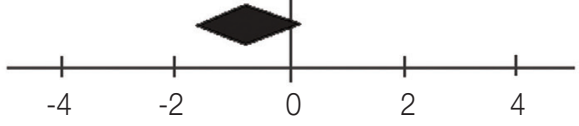

Favors experimental

Favors control

Fig. 1. Forest plot for the effect of laser therapy on dentine hypersensitivity: standardized mean differences (95\% confidence intervals) between laser therapy and active control from random effects meta-analyses. ${ }^{16}$

$\mathrm{Cl}$, confidence interval.

\section{2. 비수술적 치주염 치료에서 레이저의 효과}

치주염의 비수술적 치료는 병변에 이환된 치근 표 면의 조직을 기계적으로 제거하는 것으로, 손이나 초 음파를 이용해 스케일링과 치근 활택(scaling and root planing: SRP)을 하는 과정이 포함된다. 그러나 치주낭 과 하부 치근 표면에서 세균 군락과 그 오염물을 완전 히 제거하는 것은 전통적인 기계적 방법으로는 거의 불 가능하다. ${ }^{19}$ 특히 치근 분지부(furcation)처럼 해부적 으로 복잡한 부위에서의 SRP는 더욱 어려우며, 초음 파 스케일러를 이용할 경우 소음과 진동 및 치근 접촉
시 과민증을 일으켜 환자의 불편감을 증대시키기도 한 다. ${ }^{1} \mathrm{SRP}$ 에서 레이저를 적용할 경우 마멸, 살균 및 해독 (detoxification) 효과를 동시에 기대할 수 있다. 뿐만 아 니라 소음과 진동으로 인한 환자 불편감 유발 문제도 해 결할 수 있기에 기계적 치주 치료의 대안 또는 보조적 수단으로 주목 받아오고 있다. ${ }^{20}$

레이저를 치주염의 비수술적 치료에 이용한 임상 결 과는 다음과 같이 살펴볼 수 있다. Neil ME 등의 double blinded RCT 연구에서, Nd:YAG 레이저를 전통적 SRP 에 보조적 수단으로 적용할 경우 gingival index와 탐침 시 출혈에 있어 유의하게 우수한 결과를 보여주었다. 그 
러나 치은 부착에는 별다른 차이가 없었다. Nd:YAG 레 이저만 단독으로 적용할 경우 SRP보다 interleukin-1 $\beta$ 감 소에 있어 덜 효과적이라고 보고되었다. ${ }^{21}$ 또 다른 연구 에서는 초음파 스케일러와 비교 시, Nd:YAG 레이저 단 독으로 치주 치료를 한 경우 치은 연하에서 P. gingivalis 감소와 치은열구액에서 interleukin-1 감소에서 유의하 게 우수한 결과를 보이기도 하였다. ${ }^{22}$ 따라서 $\mathrm{Nd}: \mathrm{YAG}$ 레이저만 단독으로 이용하기 보다는 기계적 SRP의 보 조적 수단으로 이용하는 것을 권장하기도 한다. ${ }^{1}$

$\mathrm{CO}_{2}$ 레이저는 치석을 녹이거나 탄화시키기 쉽기 때 문에 치석 제거에 적합하지 못한 것으로 보인다. ${ }^{21}$ 또 한 SRP에서 $\mathrm{CO}_{2}$ 레이저와 초음파 스케일러의 효과 를 비교한 실험에서는, 레이저 치료 시 P. gingivalis와 interleukin-1의 유의미한 감소 효과가 관찰되지 않았 다. ${ }^{22}$

비수술적 치주 치료에서 diode 레이저의 활용은 비교 적 최근에 연구되기 시작하였다. Diode 레이저를 보조적 으로 이용할 경우 치주낭에서 A. actinomycetemcomitans 등의 세균 감소를 기대할 수 있다. ${ }^{23}$ 또 다른 연구에서는, $\mathrm{SRP}$ 의 보조적 요법으로 diode 레이저를 펄스 형태로 적 용 시 유의한 개선 효과가 관찰되지 않았다..$^{24}$ 2013년에 수행된 메타 분석 연구에서는, diode 레이저가 SRP에 추가적인 이득 효과를 주지 않는 것으로 정리되었다. 그 러나 메타 분석의 포함 기준- 만성 치주염으로 진단된 환자를 대상으로 RCT로 6개월 이상 추적 조사한 연구을 만족하는 연구는 오직 5 개였다. 이 가운데 3 개의 연 구는 높은 수준의 편향을 내포한 것으로 분석되었다. ${ }^{25}$ 따라서 diode 레이저의 보조적 치료 효과를 확인하기 위 해서는 더 많은 연구가 필요할 것으로 보인다.

여러 종류의 레이저 가운데 기존의 기계적 SRP를 대 체할 것으로 가장 기대되는 것은 Er:YAG 레이저이다. Er:YAG 레이저가 전통적 SRP 치료보다 탐침 시 출 혈, 치주낭 깊이 그리고 부착 수준의 향상을 보였다. ${ }^{26} 6$ 개월 추적 조사에서 레이저 치료가 초음파 스케일러와 유사한 효과를 보여주었다. ${ }^{27}$ 시술 후 2 년 간 비교 시, Er:YAG 레이저 치료가 초음파 스케일러보다 치주낭 깊 이가 감소와 부착 수준 향상에서 유의한 효과를 나타낸 연구 결과도 있다. ${ }^{28}$ 또한 레이저 치료가 새로운 백악질 형성을 촉진한다는 주장도 있다. ${ }^{29}$ 그러나 SRP 장치 별 로 환자 불편감을 평가한 연구에서는 초음파 스케일링 이 Er:YAG 레이저보다 더 환자 만족도가 큰 것으로 보 고되기도 하였다. ${ }^{30}$ 따라서 Er:YAG 레이저를 치주 치료
가 전통적 SRP와 유사한 효과를 나타내는지 혹은 더 우 수한 임상 결과를 보이는지 명확한 결론을 내려줄 추가 적 연구가 요구된다. 또한 치은 연하에 효과적으로 전달 되고 환자의 불편감을 감소시킬 수 있도록 레이저 장치 의 tip 개선 등이 필요하다.

\section{3. 임플란트 주위염 치료에서 레이저의 효과}

임플란트 주위염을 치료하는 이상적인 프로토콜에 대 한 합의는 아직 없지만, 플라스틱 큐렛 등을 이용해 오 염된 조직을 제거하는 것이 추천되어 왔다. ${ }^{31}$ 그러나 이 러한 기계적 제거 방식만으로는 임플란트 표면으로부터 세균과 오염된 산물을 완전히 제거하기 어렵다. ${ }^{32}$ 기계 적 제거 외에 화학 약품이나 항생제 투여 등을 병행하는 보조적 치료 요법이 추천되기도 하지만, 그 효과가 미비 하거나 ${ }^{33}$ 항생제 내성 등의 부작용에 대한 우려가 있어 왔다.

따라서 레이저를 이용해 오염물을 제거하고 임플란 트 표면을 정화하는 요법이 주목을 받고 있다. 일부 연 구에서, Nd:YAG 레이저는 임플란트 표면을 비가역적 으로 변화시키는 것으로 나타났다. ${ }^{34,35} \mathrm{CO}_{2}$ 레이저는 임 플란트 표면을 손상시키지 않고 정화 작용을 하는 것으 로 보고되었다. ${ }^{36}$ 임플란트 주위염에서 연조직 절개와 $\mathrm{CO}_{2}$ 레이저 치료를 병행할 경우 부착 수준의 유의한 향 상이 있었지만, 4 개월 후의 비교 평가에서는 레이저 치 료에 이득이 없는 것으로 나타났다. ${ }^{37}$ Diode 레이저 역 시 임플란트의 표면의 정화 효과가 있지만, ${ }^{34}$ 부적절하 게 적용한 경우 임플란트-골 계면에서 열을 발생시키고, chlorhexidine을 이용한 전통적 치료법보다 덜 효과적인 것으로 나타났다. ${ }^{38}$

Er:YAG 레이저는 오염된 임플란트 표면의 정화 뿐만 아니라, 연조직과 경조직을 마멸시켜 염증 조직을 제거 하는 효과까지 있기에 임플란트 주위염 치료에서 가장 효과적인 레이저로 기대된다. Er:YAG 레이저는 임플란 트 표면을 손상시키지 않으며, 조사된 표면에서 조골 세 포의 부착 속도에 영향을 주지 않았다..$^{39}$ 또한 Er:YAG 레이저 조사 시 오염된 지대주와 매식제 표면에서 치석 과 치태 제거가 효과적인 것으로 나타났다. ${ }^{40}$ 체외 연구 에서는 플라스틱 큐렛에 chlorohexidine이나 초음파를 적용한 치료보다 Er:YAG 레이저가 더 효과적이라는 주 장도 있다. ${ }^{32}$ 임상 연구에서는, Er:YAG 레이저 치료가 플라스틱 큐렛을 통한 기계적 정화와 유사한 정도의 치 


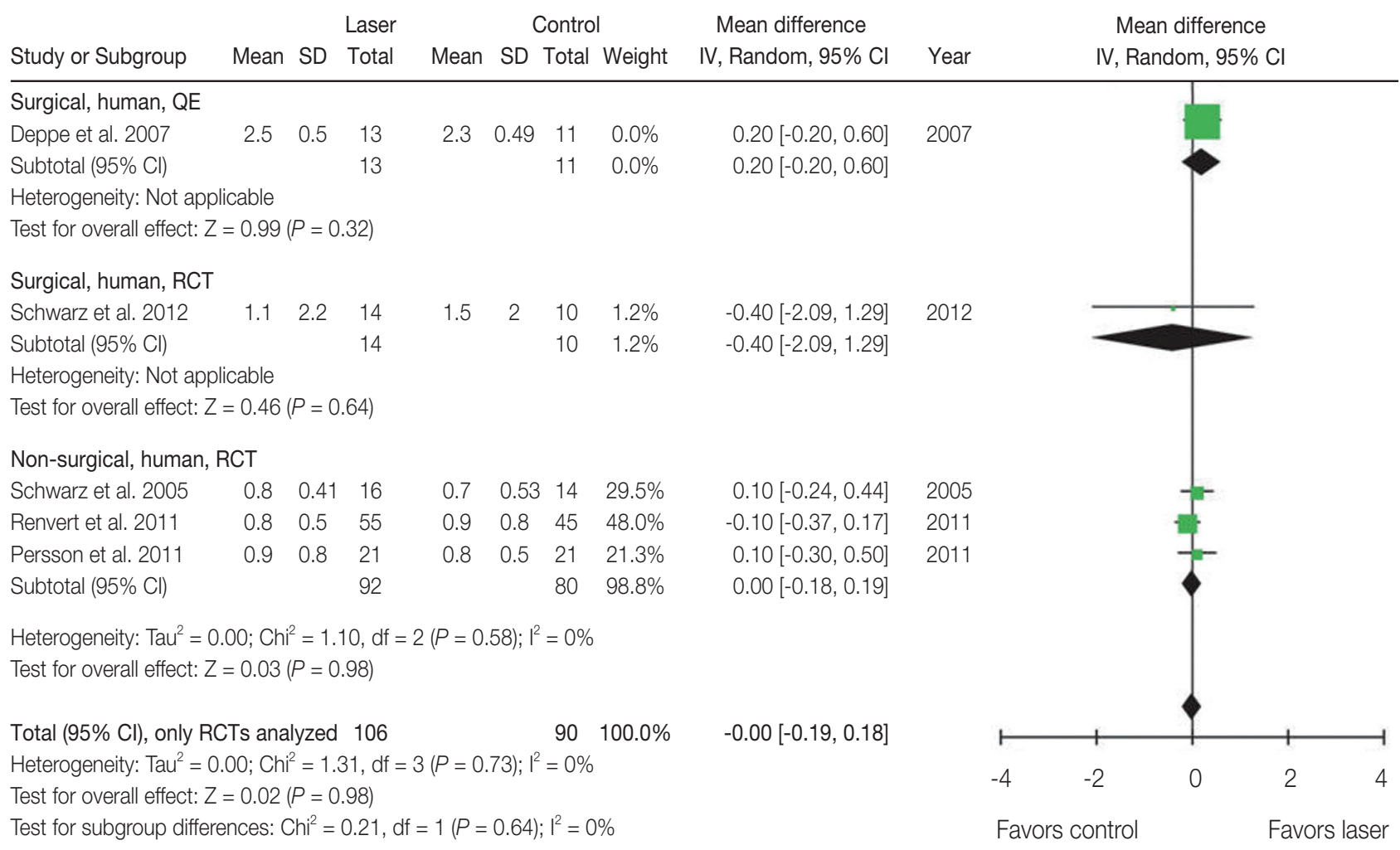

Fig. 2. Meta-analysis for probing depth reduction among selected studies. For non-surgical interventions, three RCTs were included and the weighted mean difference was $0.00 \mathrm{~mm}(95 \% \mathrm{Cl}=-0.18$ to $0.19 \mathrm{~mm}, P=0.98) .{ }^{42}$

$\mathrm{Cl}$, confidence interval.

료 효과를 보이는 것으로 나타났다. ${ }^{41}$

최근에 Mailoa 등이 임플란트 주위염에서 레이저의 치료 효과에 대해 체계적 문헌 고찰 결과, 비수술적 레 이저 치료의 RCT 임상 연구는 단지 3개 뿐이었고 모두 $\mathrm{CO}_{2}$ 또는 Er:YAG 레이저를 이용하였다. 메타 분석을 시행한 결과, 치주낭 감소에 있어서 레이저는 기존의 통 상적 정화 방식과 차이가 없는 것으로 나타났다(Fig. 2). ${ }^{42}$ 그러나 여기에 포함된 임상 연구는, 표본 수가 작고 추 적 조사 기간이 짧기에 그 결과를 단언하기에는 아직 시 기상조로 보인다.

\section{결론}

레이저를 통한 비접촉 에너지 전달 방식은 핸드피스 나 큐렛, 초음파 스케일러와 같은 기계적 접촉 방식을 대체할 유력한 후보임이 분명하다. 약제의 도움 없이 상 아 세관을 폐색하고 신경말단에 진정 효과를 주는 기기 는 레이저가 유일하다. 상용화된 레이저 장치가 상아질 지각과민증과 치주 치료를 위해 사용되고 있음에도 불 구하고, 아직 그 임상적 효능에 대해서는 의견이 분분
하다. 최근에 발표된 체계적 문헌 고찰 연구를 중심으 로 레이저의 치료 효과에 대해 살펴본 결과, 신뢰할만한 무작위 비교 연구의 수가 극히 미비함을 확인할 수 있 었다. 레이저 종류에 따라서도 임상 효능에 분명한 차 이를 보여주었다. 따라서, 레이저의 효능에 대한 판단은 잘 설계된 임상 연구가 상당수 이루어진 다음으로 미루 어야 할 것이다. 이와 함께, 병변까지 효과적으로 에너 지를 송달할 수 있고 파장과 출력을 다양한 범위로 조절 가능한 치과용 레이저 개발을 기대해 본다.

\section{Acknowledgments}

본 연구는 산업통상자원부의 재원으로 신성장동력 장비경쟁력 강화사업의 지원에 의하여 이루 어진 것임 (10047615).

\section{References}

1. Ishikawa I, Aoki A, Takasaki AA, Mizutani K, Sasaki KM, Izumi Y. Application of lasers in peri- 
odontics: true innovation or myth? Periodontol 2000 2009;50:90-126.

2. Goldman L, Hornby P, Meyer R, Goldman B. Impact of the laser on dental caries. Nature 1964; 203:417.

3. Wigdor H, Abt E, Ashrafi S, Walsh JT Jr. The effect of lasers on dental hard tissues. J Am Dent Assoc 1993;124:65-70.

4. Hale GM, Querry MR. Optical constants of water in the 200-nm to 200-microm wavelength region. Appl Opt 1973;12:555-63.

5. Lee YB, Painless treatment using water laser is false hype. The Daily Dental. November 2, 2006.

6. Matsumoto K, Funai H, Shirasuka T, Wakabayashi H. Effects of Nd:YAG-laser in treatment of cervical hypersensitive dentine. Jpn J Conserv Dent 1985;28:760-5.

7. Sgolastra F, Petrucci A, Gatto R, Monaco A. Effectiveness of laser in dentinal hypersensitivity treatment: a systematic review. J Endod 2011;37:297303.

8. Orchardson R, Peacock JM, Whitters CJ. Effect of pulsed Nd:YAG laser radiation on action potential conduction in isolated mammalian spinal nerves. Lasers Surg Med 1997;21:142-8.

9. Corona SA, Nascimento TN, Catirse AB, Lizarelli RF, Dinelli W, Palma-Dibb RG. Clinical evaluation of low-level laser therapy and fluoride varnish for treating cervical dentinal hypersensitivity. J Oral Rehabil 2003;30:1183-9.

10. Tengrungsun T, Sangkla W. Comparative study in desensitizing efficacy using the GaAlAs laser and dentin bonding agent. J Dent 2008;36:392-5.

11. Zhang C, Matsumoto K, Kimura Y, Harashima T, Takeda FH, Zhou H. Effects of $\mathrm{CO}_{2}$ laser in treatment of cervical dentinal hypersensitivity. J Endod 1998;24:595-7.

12. Moritz A, Schoop U, Goharkhay K, Aoid M, Reichenbach P, Lothaller MA, Wernisch J, Sperr W. Long-term effects of $\mathrm{CO}_{2}$ laser irradiation on treatment of hypersensitive dental necks: results of an in vivo study. J Clin Laser Med Surg 1998;16:211-5.

13. Kobayashi K, Yamaguchi H, Kumai A, Tanaka M, Sakuraba E. Nomura T, Nakamura J, Arai T. Pain relief effects of Nd:YAG laser irradiation on den- tin hypersensitivity during periodontal treatment. J Jpn Soc Periodontol 1999;41:180-7.

14. Schwarz F, Arweiler N, Georg T, Reich E. Desensitizing effects of an Er:YAG laser on hypersensitive dentine. J Clin Periodontol 2002;29:211-5.

15. Birang R, Poursamimi J, Gutknecht N, Lampert F, Mir M. Comparative evaluation of the effects of Nd:YAG and Er:YAG laser in dentin hypersensitivity treatment. Lasers Med Sci 2007;22:21-4.

16. Cunha-Cruz J. Laser therapy for dentine hypersensitivity. Evid Based Dent 2011;12:74-5.

17. Vieira AH, Passos VF, de Assis JS, Mendonça JS, Santiago SL. Clinical evaluation of a 3\% potassium oxalate gel and a GaAlAs laser for the treatment of dentinal hypersensitivity. Photomed Laser Surg 2009;27:807-12.

18. Lier BB, Rösing CK, Aass AM, Gjermo P. Treatment of dentin hypersensitivity by $\mathrm{Nd}: \mathrm{YAG}$ laser. J Clin Periodontol 2002;29:501-6.

19. Adriaens PA, Edwards CA, De Boever JA, Loesche WJ. Ultrastructural observations on bacterial invasion in cementum and radicular dentin of periodontally diseased human teeth. J Periodontol 1988;59:493-503.

20. Aoki A, Sasaki KM, Watanabe H, Ishikawa I. Lasers in nonsurgical periodontal therapy. Periodontol 2000 2004;36:59-97.

21. Tucker D, Cobb CM, Rapley JW, Killoy WJ. Morphologic changes following in vitro $\mathrm{CO}_{2}$ laser treatment of calculus-ladened root surfaces. Lasers Surg Med 1996;18:150-6.

22. Miyazaki A, Yamaguchi T, Nishikata J, Okuda K, Suda S, Orima K, Kobayashi T, Yamazaki K, Yoshikawa E, Yoshie H. Effects of Nd:YAG and $\mathrm{CO}_{2}$ laser treatment and ultrasonic scaling on periodontal pockets of chronic periodontitis patients. J Periodontol 2003;74:175-80.

23. Moritz A, Gutknecht N, Doertbudak O, Goharkhay K, Schoop U, Schauer P, Sperr W. Bacterial reduction in periodontal pockets through irradiation with a diode laser: a pilot study. J Clin Laser Med Surg 1997;15:33-7.

24. Borrajo JL, Varela LG, Castro GL, RodriguezNuñez I, Torreira MG. Diode laser (980 nm) as adjunct to scaling and root planing. Photomed Laser 
Surg 2004;22:509-12.

25. Sgolastra F, Severino M, Gatto R, Monaco A. Effectiveness of diode laser as adjunctive therapy to scaling root planning in the treatment of chronic periodontitis: a meta-analysis. Lasers Med Sci 2013; 28:1393-402.

26. Schwarz F, Sculean A, Georg T, Reich E. Periodontal treatment with an Er: YAG laser compared to scaling and root planing. A controlled clinical study. J Periodontol 2001;72:361-7.

27. Sculean A, Schwarz F, Berakdar M, Romanos GE, Arweiler NB, Becker J. Periodontal treatment with an Er:YAG laser compared to ultrasonic instrumentation: a pilot study. J Periodontol 2004;75: 966-73.

28. Crespi R, Capparè P, Toscanelli I, Gherlone E, Romanos GE. Effects of Er:YAG laser compared to ultrasonic scaler in periodontal treatment: a 2-year follow-up split-mouth clinical study. J Periodontol 2007;78:1195-200.

29. Schwarz F, Jepsen S, Herten M, Aoki A, Sculean A, Becker J. Immunohistochemical characterization of periodontal wound healing following nonsurgical treatment with fluorescence controlled Er:YAG laser radiation in dogs. Lasers Surg Med 2007;39: 428-40.

30. Derdilopoulou FV, Nonhoff J, Neumann K, Kielbassa AM. Microbiological findings after periodontal therapy using curettes, Er:YAG laser, sonic, and ultrasonic scalers. J Clin Periodontol 2007;34:58898.

31. Roos-Jansåker AM, Renvert S, Egelberg J. Treatment of peri-implant infections: a literature review. J Clin Periodontol 2003;30:467-85.

32. Schwarz F, Sculean A, Romanos G, Herten M, Horn N, Scherbaum W, Becker J. Influence of different treatment approaches on the removal of early plaque biofilms and the viability of SAOS2 osteoblasts grown on titanium implants. Clin Oral Investig 2005;9:111-7.

33. Schou S, Holmstrup P, Jørgensen T, Skovgaard LT, Stoltze K, Hjørting-Hansen E, Wenzel A. Implant surface preparation in the surgical treatment of experimental peri-implantitis with autogenous bone graft and ePTFE membrane in cynomolgus mon- keys. Clin Oral Implants Res 2003;14:412-22.

34. Romanos GE, Everts H, Nentwig GH. Effects of diode and $\mathrm{Nd}: \mathrm{YAG}$ laser irradiation on titanium discs: a scanning electron microscope examination. J Periodontol 2000;71:810-5.

35. Kreisler M, Götz H, Duschner H. Effect of Nd:YAG, Ho:YAG, Er:YAG, $\mathrm{CO}_{2}$, and GaAIAs laser irradiation on surface properties of endosseous dental implants. Int J Oral Maxillofac Implants 2002;17:202-11.

36. Kato T, Kusakari H, Hoshino E. Bactericidal efficacy of carbon dioxide laser against bacteria-contaminated titanium implant and subsequent cellular adhesion to irradiated area. Lasers Surg Med 1998; 23:299-309.

37. Deppe H, Horch HH, Neff A. Conventional versus $\mathrm{CO}_{2}$ laser-assisted treatment of peri-implant defects with the concomitant use of pure-phase beta-tricalcium phosphate: a 5-year clinical report. Int J Oral Maxillofac Implants 2007;22:79-86.

38. Kreisler M, Kohnen W, Marinello C, Schoof J, Langnau E, Jansen B, d'Hoedt B. Antimicrobial efficacy of semiconductor laser irradiation on implant surfaces. Int J Oral Maxillofac Implants 2003; 18:706-11.

39. Schwarz F, Rothamel D, Sculean A, Georg T, Scherbaum W, Becker J. Effects of an Er:YAG laser and the Vector ultrasonic system on the biocompatibility of titanium implants in cultures of human osteoblast-like cells. Clin Oral Implants Res 2003;14:784-92.

40. Matsuyama T, Aoki A, Oda S, Yoneyama T, Ishikawa I. Effects of the Er:YAG laser irradiation on titanium implant materials and contaminated implant abutment surfaces. J Clin Laser Med Surg 2003;21: 7-17.

41. Schwarz F, Sculean A, Rothamel D, Schwenzer K, Georg T, Becker J. Clinical evaluation of an Er:YAG laser for nonsurgical treatment of periimplantitis: a pilot study. Clin Oral Implants Res 2005;16:44-52.

42. Mailoa J, Lin GH, Chan HL, MacEachern M, Wang HL. Clinical outcomes of using lasers for peri-implantitis surface detoxification: a systematic review and meta-analysis. J Periodontol 2014;85:1194-202. 


\section{상아질 지각과민증과 치주 처치에서 레이저의 이용}

\section{남궁철 ${ }^{1}$, 이종호 ${ }^{2}$, 금기연 $^{3}$, 임영준 $^{1 *}$}

서울대학교 치의학대학원 및 구강과학연구소 ${ }^{1}$ 치과보철학교실, ${ }^{2}$ 구강악안면외과학교실, ${ }^{3}$ 치과보존학교실

레이저가 치과 분야에 도입된 지 상당한 시간이 지났지만, 아직 그 효능에 대해서는 의견이 분분하다. 본 논문에서는 지각과민증과 치주 처치에 있어 레이저가 갖는 효능에 대한 최근 연구 결과들을 되짚어보고자 한다.

(구강회복응용과학지 2014;30(4):307-14)

주요어: 레이저; 지각과민; 치주염; 임플란트 주위염; 세정

*교신저자: 임영준

(110-769) 서울특별시 종로구 대학로 101 서울대학교 치의학대학원 치과보철학교실

Tel: 02-2072-3816 | Fax: 02-2072-3860 || E-mail: limdds@snu.ac. kr

접수일: 2014년 7월 14일 | 수정일: 2014년 8월 10일 | 채택일: 2014년 8월 14일 